\title{
A Study on the Strategy of Improving the Ability of Young Teachers in Private Universities -- Taking Shaanxi Private Universities as Examples
}

\author{
Liu Dongsheng \\ Xi'an International University, Shaanxi Xi'an, China, 710077
}

Keywords: private universities, young teachers, professional ability improvement

\begin{abstract}
University teachers are the main undertaker of the training of senior specialized personnel, and the level of teachers' ability directly determines the education quality level of universities. As the main force of private universities, the professional ability of young teachers has the greatest impact on the survival and sustainable development of private universities. Therefore, it is of great significance for the development of universities to improve the professional ability of young teachers. From the factors influencing the improvement of young teachers in private universities, this paper takes Shaanxi private universities as examples to explore the ways to improve their professional competence.
\end{abstract}

Universities are the institutions for cultivating a large number of high-quality innovative talents who can meet the needs of developing the society as a whole. Teachers are the most important resource in universities. With the continuous expansion of education, young teachers have become the main force among university teachers in private universities. The proportion of young teachers under 35 in most private universities in Shaanxi is over $50 \%$. Although they have a higher educational degree, many of them have not received systematic training on teaching methodology prior to their teaching, and their lack of experience has restricted their professional development. Therefore, how to improve the quality of private college teachers is not only one of the main problems that the organizers and the management of private universities need to solve, but also the problem that all private university teachers have to consider.

The process of improving teachers' professional quality and ability is that teachers gradually improve their comprehensive quality through pre-service training, lifelong professional training and continuous acquisition of education professional knowledge and skills. Start from analyzing the factors that affect the professional growth of young teachers in private universities, this paper tries to explore the methods on improving their professional abilities.

\section{Status quo of teachers in private universities in Shaanxi}

There are 30 private universities in Shaanxi. It is mentioned in the paper "A Study on the Team Construction of Teachers in Private Universities in the Era of Big Data--Taking Shaanxi Private Universities as Examples" that teachers with bachelors and master's degree in private universities in Shaanxi account for $50 \%$ and $45 \%$ respectively, and only $5 \%$ of them obtained doctoral degrees. 
Meanwhile, by the end of 2014, teachers with doctoral degrees in public universities had reached about $65 \%$. In terms of professional titles, teachers with senior professional titles in public universities and private ones account for $25 \%$ and $10 \%$ respectively. Accordingly, public school teacher do better in academic research in that a higher percent of their papers are published in core journals. It can be safely concluded that there is a huge gap in educational background and scientific research between teachers in public universities and those in private ones.

\section{Factors influencing the ability improvement of young teachers in private universities in Shaanxi}

\subsection{Huge pressure in scientific research}

Despite of the fact that some private universities in Shaanxi province are just encouraging teachers to do scientific research, many of them impose high demand on the teachers to do scientific research. In some private universities, it is required that certain number of papers have to be published each year in a certain period of time. While at the same time, enough efforts have not been paid to educate or train the teachers to conduct scientific research, which not only increase the teachers' pressure, wasting their time on worrying about conducting research, but also discouraging their pursuit in presenting good lectures to the students, as too much time and effort have to be put into their academic research. Although teachers can gain more knowledge through conducting scientific research, too much pressure in doing it can arose teachers' repugnance toward it. Therefore, time and patience should be given to the young teachers to allow them to gradually improve their ability in both teaching and doing scientific research.

\subsection{Deficient incentive system}

At present, the incentive system in many private universities in Shaanxi is far from perfect and lack of humanity and flexibility. Some universities attach more importance to moral encouragement and pay less attention on material reward, while others do just the opposite. But generally though certainly not always, private universities are competing with each other on their achievements on academic research rather than on their teaching performances, which is also the case in most public universities. The reason for this phenomenon is caused largely because it is easier to evaluate a person's achievement on scientific research than on teaching, for teachers' efforts in making preparations for presenting high quality lectures, marking the homework of the students and things of these sorts are often go unnoticed, which seriously undermines a teacher's motivation to reflect on their teaching performance and improve their teaching methodology.

\subsection{Low income}

As private universities, financial support from the government is very limited, so private universities have to assume sole responsibility for their profits or losses. For this reason, compared with teachers in private colleges, the salary of teachers in private universities is relatively low. Under this circumstance, young teachers in private universities are more motivated to pursue a higher degree so as to obtain a job at public universities, instead of focusing their attention on teaching or doing scientific research. And for those who are not interested in pursuing higher degrees, they are more likely to make efforts on doing scientific research with the purpose to promote their professional titles or teach more classes in order to increase their income. And none of these circumstances are beneficial for young teachers to improve their teaching ability. 


\subsection{Job burnout among teachers}

Burnout refers to physical or emotional exhaustion, especially as a result of long-term stress of dissipation, which is mostly often happen to teachers and doctors. And unfortunately, it is not only happen to middle or senior teachers, but young teachers as well. In recent years, as the enrollment of college entrance examination is decreasing year by year, all universities try their best to attract more students. The competition among private universities is even more intense. In order to solve the problem, private universities have to enroll as many students as possible, which make the admission score of private universities get lower and lower. To make the situation worse, some private university students are admitted through comprehensive evaluation and enrollment without taking the college entrance examination. Therefore, there is a general lack of professional knowledge and lack of serious learning attitude among students in private universities. The lack of scientific knowledge of students makes it more difficult for teachers to carry out the teaching of university courses. In addition, many private colleges lack the awareness of respecting teachers, which greatly reduces the sense of achievement and dignity of teachers and severely discourages teachers' passion for teaching. Young teachers come to the private universities with the hope of being a great teacher to their students, but when their efforts goes unappreciated, they often suffer from a sense of hopeless and helpless, and so their passion toward teaching usually go away very quickly after only a few year of teaching. Teachers teaching three-year students are more likely to experience it earlier than those teaching four-year students. Furthermore, high pressure on both scientific researches and teaching missions make teachers mentally and physically exhausted. Under this circumstance, teachers are just trying to finish their teaching instead of enjoying their teaching. Some spiritually tormented and disillusioned teachers even quit their jobs. Therefore, it is quite unlikely for them to focus their attention on improving their teaching ability.

\subsection{Unpredictability in professional title promotion}

From 2017, private universities have been empowered to promote the professional titles of their teachers. Unfortunately, it is getting more difficulty for teachers in some private universities to promote their professional titles in that more requirements are imposed on them. Other than meeting such general requirements as publishing three papers in core journals, hosting or participating research programs, some private universities impose other requirements on the teachers, such as assisting students to win competitions, assisting students in passing postgraduate exams, etc. And even the teacher meet all the requirements, they have to be voted by experts of the university, which is totally beyond the control of the teachers. This unpredictability in professional title promotion increase the pressure of the teachers even more and some teachers simply give up on improving their professional titles and their passion in teaching decreased as well for lacking of confidence in their career.

\subsection{Other pressures}

Young teachers are not only in the period of growth and development of their career, but also in the period of starting their families. This is the stage of period that in most cases, a family is to be build, and an apartment has to be bought, or a family to support, while the salary of teachers in private universities is generally low or unsatisfactory, which brings heavy economic pressure to private teachers, and affects their physical and mental state, making many teachers unable to put necessary energy to improve their professional ability. 


\section{Suggestions on improving the professional ability of young teachers in private universities}

\subsection{For private universities, the following measures can be taken to improve the professional ability of the young teachers}

\subsubsection{Conducting professional training}

In different stages, guidance and training should be provided for young teachers on class teaching and management and conducting scientific research. The first step to building a high-quality professional teaching team is to conduct pre-service training. The teacher development centers in private universities should formulate a scientific teacher training program according to the needs of individual development of teachers, and solicit teachers' opinions widely to ensure the feasibility and effectiveness of the training programs. At present, many universities are not doing enough in this regard. There are quite a few graduate students and doctoral students who start their teaching work without teaching experience, which will easily cause their psychological panic and will also make students feel unsatisfied toward the teachers' ability, which will seriously affect the teaching and learning effect. Therefore, private universities should conduct training for new teachers in advance, and meanwhile, encourage the experienced teachers to train new teachers on how to make it easier for students to learn in a simple and understandable way.

Secondly, private universities should allocate special funds and actively organize teachers to carry out various professional trainings. The training here includes not only the training on teaching methodology as a whole, but also on their professional training. For example, for English teachers, they can invite domestic and foreign experts for experience exchange so that teachers can be exposed to the latest teaching methods and concepts. Offering on-line courses for teachers are also a good training method to teachers with various interests in their professional fields. Special funds should also be allocated to teachers to attend various kinds of lectures or workshops to allow teachers to keep up with the latest development in their professional fields. Other activities such as teaching or academic salons can also be held to strengthen the interaction and learning among teachers.

\subsubsection{Perfecting teacher evolution system}

Universities should develop individualized incentive mechanism to assess teachers of different types. Teachers with their priority on presenting high-quality lectures should be assessed on their teaching effects through the evaluation of the students and experts. Teachers who are more interested in conducting scientific research can be assessed through their academic accomplishments, which include the paper they published and the programs they have conducted. Meanwhile, salons can be held between teachers of teaching type and academic type to strengthen their interaction and learning from each other. Various kinds of awards, both material and spiritual reward, should be given to teachers who perform better in teaching competitions or assist students in taking part in various kinds of competitions to encourage teachers to improve themselves through a variety of activities.

\subsubsection{Creating a respectful campus cullture}

China has always had the tradition of showing great respect to the teachers. Nowadays, however, the idea of respecting teachers has been challenged in the past decades, especially with the arrival of the information age, when teachers are no longer the most important source of knowledge, which break the balance between the harmonious relationship between teachers and students. With less and less respect from students, teachers are discouraged from improving their teaching methodology. 
Therefore, if universities can rebuild the campus culture in which students show respect to their teachers, teachers will be more motivated to do better in their teaching to live up to the expectation of their students.

\subsubsection{Increasing the income of young teachers}

It is necessary for the management of private universities to increase their teachers' benefits such as pension, medical, etc. as well as their salary so that young teachers can be free from anxieties caused by limited income and put their heart and soul into improving their ability in teaching and doing scientific research. At the same time, private universities can put their advantages into full play and conduct cooperation with other institutions or companies or even start their own business in areas that teachers specialize in. For example, teachers in English major can start a translating company. In this way, both teachers and students can not only increase their experience in doing translation, but also increase their income. The materials need to be translated can serve as real examples for teachers to apply translation theories into their teaching of translation if the materials are not confidential. Teachers and students can also develop their team work spirit, which is a very important quality for teachers to conduct research programs.

\subsection{Teachers in private universities can improve their professional ability through the following methods:}

\subsubsection{Reflecting on teaching on a regular basis}

According to G.J.Posner, an American psychologist, the formula for a teacher's growth is as follows: growth $=$ experience + reflections. Wang Yanling, a Chinese scholar, also pointed out that a teacher's reflection journal should be a record of the teacher's own teaching activities and conclusions on their gains and losses in their teaching process. Teachers can review, analyze and reflect on their teaching procedure and find better way to conduct teaching activities and improve their teaching ability in the process. Keeping a journal is an important measure for teachers to develop their ability, perfect their teaching art and realize their self-worth. In addition, journals should be reviewed on a regular basis to make evaluation on their progress in order to further improve their teaching. Only when teachers are committed into improving their teaching ability and are excel at drawing conclusions and making progress on their teaching can they find their own characteristic style in teaching and improve their teaching ability in every aspect. It can be concluded that keeping journals is an effective way to improve a teacher's teaching ability.

\subsubsection{Be committed in lifelong learning}

Teachers should bear in mind that learning is a lifelong mission. As knowledge and technology updates rapidly, each teacher has to learn different things every day, which not only include new teaching methodology, but the latest teaching technique as well. Mooc, flipped classroom, and things of these sorts should be learned to keep up with the time. New teaching measure, such as applying WeChat or other APPs to conduct class teaching should also be learned to make it more effective for students to master professional skills. Meanwhile, core journals in related professional fields should be read regularly to keep up with the latest developments.

Meanwhile, teachers in private universities should take initiative in attending various salons, seminars or workshops to learn specialized knowledge. Due to limited funds for teachers in private universities to attend various kinds of workshops, it is not realistic for the teachers to attend workshops very often. Yet, they can pay attention to some public lectures or salons held by some public universities. 
In addition, attending the class of experienced teachers is also a good and direct way to improve the teaching ability of the young teachers. Young teachers can attend as much as lectures to obtain new ideas and absorb the ideas fit for their classes.

\subsubsection{Communicating with students}

To establish a harmonious relation with the students, efforts should be made by teachers to communicate with the students. Since students do not learn from teachers they do not like, it is important for teachers to communicate with their students more, and understand them so that their teaching can be conducted more smoothly. With new technology, it is getting easier for teachers to communicate with each other. With WeChat and other tools, teachers and students can communicate with each other anytime and anywhere. Teachers should make the best of the tools to talk with students over things like their difficulties, problems in their studies. Feedbacks from students are valuable sources for teachers' reflections on their teaching performance.

\subsubsection{Nurturing a peaceful mind}

Nowadays, with the rapid development of the social economy, the gap between the rich and the poor is getting larger. In addition, gap also exists between teachers in public universities and those in private ones. Under these circumstances, more and more people are focusing their attention on making more money. Unfortunately, teaching is not a high paid job, but a low paid one. Therefore, a teacher must nurture a peaceful mind so as to concentrate on improving their teaching ability instead of trying to teach as many classes as possible to increase their income. Too much attention been paid to fame and wealth will certainly distract young teachers' attention from improving their teaching ability and conducting scientific research. Only those who do not care about fame and fortune will devote themselves to the teaching professional and improve their overall ability. Therefore, it is essential for teachers in private universities to nurture a peaceful mind.

\section{Conclusion}

The ability improvement of teachers from private universities requires efforts from both the management of the universities and the teachers as well. Only when the management of the universities makes up their mind to improve the teaching effects of the teachers will they make efforts necessary to help teachers improve their abilities. And only when teachers in private universities focus their attention on improving themselves instead of gaining fame and fortune will them make substantial progress in the professional fields and make contribution to cultivating qualified and creative talents for the development of the society.

\section{References}

[1] Guo Jing, Wang Xuecheng. A Study on the Team Construction of Teachers in Private Universities in the Era of Big Data--Taking Shaanxi Private Universities as an Example. Journal of Inner Mongolia Normal University, 2016 (29).

[2] Zou Chenhua, Huang Lianjie. Research on the Development of Young Teachers in Universities in China from Multiple Perspectives. Beijing: Beijing Institute of Technology Press, 2017.

[3] Wu Qinghua, Guo Lijun. Research on the Development of Young Teachers in Local Universities. Beijing: Economy and Management Publishing House, 2017.

[4] Wang Lu. On the Present Situation and Countermeasures of the Construction of Private College Teachers. New Curriculum Research, 2016 (06).

[5] Li Li. Analysis on the Status Quo of Teachers in Private Universities and the Countermeasure. Journal of Wuhan Metallurgical Managers Institute. 2017 (27).

[6] Zhao Li, Shao Changwei. The Sustainable Development Strategies for Teachers in Private Universities. Journal of Jilin Engineering Normal University. 2016 (32). 